\title{
Emotional Intelligence: Does Emotional Intelligence Scores Differ in Variant Nursing Leadership Levels?
}

\author{
Rachel W. Njoroge ${ }^{1}$, David Oginde, $\mathbf{P h D}^{2}$, Nickson Lumwagi Agusioma, $\mathbf{P h D}^{\mathbf{3}}$ \\ ${ }^{l}$ PhD Student at Pan African Christian University, Assistant Director of Nursing Services; \\ The Nairobi Hospital, Kenya \\ ${ }^{2}$ Chancellor, Pan African Christian University, Bishop of Christ is the Answer Ministries, \\ Kenya \\ ${ }^{3}$ Lecturer, Multimedia University of Kenya, Nairobi
}

\begin{abstract}
In the recent past Emotional intelligence has evoked a lot of attention in leadership. While intelligence quotient and technical skills contribute considerably to leadership, emotional intelligence is the gold standard for leadership. This study explores the differences in emotional intelligence scores between the mid-level managers and of the team leaders. Therefore, a quantitative approach was adopted. Correlational study design was employed to explore the emotional intelligence scores between the two levels of leadership in a private city hospital. An adopted seven-Likert scale emotional intelligent inventory; self-administered tool was used in data collection from the two groups of leaders. Data was analysed using Statistical Package for the Social Sciences (SPSS). The results of the two groups was generated and correlated, and the standard deviation was identified. The findings of the study demonstrated that the mid-level managers demonstrated higher levels of emotional intelligence score in some facets like flexibility with a standard deviation of 38.1, and optimism with a standard deviation of 17.7. On the contrary, the team leaders demonstrated higher emotional intelligence score on emotional self-control with a standard deviation of 2.1 and an initiative with a standard deviation of 3.5. The conclusion was drawn that, in deed, emotional intelligence is a valuable construct in leadership. The senior leaders had higher emotional intelligence scores than the junior leaders. There is need for further study using variant triangulated tools to measure emotional intelligence comprehensively.
\end{abstract}

\section{Key Words: Emotional intelligence, leaders, leadership}

DOI 10.7176/ijcab.v3iIII.29, URN:nbn:de:0000ijcab.v3iIII.296

\section{Cite this Article:}

Njoroge, R., Oginde, D., \& Agusioma, N. (2019). Emotional Intelligence: Does Emotional Intelligence Scores Differ in Variant Nursing Leadership Levels? International Journal of Current Aspects, 3(III), 41-57. http://journals.ijcab.org/journals/index.php/ijcab/article/view/29

\section{INTRODUCTION}

Emotional intelligence (EI) is defined as "the capability to understand our emotions and deal with them effectively, and to understand, and successfully manage the emotions of others" (Goleman, 1995; Mayer Salovey, 1997). Emotions play a great role in the society and have generated a lot of interest especially at the work place (Cherniss, 2003). The concept of EI has, therefore, has gained interest, and because emotions play a key role in human life, people are equally variable in the way they perceive events of life, and the differences immensely affect how individuals adapt in different concepts of life (Cherniss, Roche, Barbarasch and Friedman, 2016). The history of EI goes back to Thorndike (1920) as cited by Cherniss, et, al. (2016) who 
argued that collective intelligence is distinctive compared to cognitive intelligence and therefore he proposed the development of EI measures. Similarly, Austin et al. (2007) found that between EI and social functioning there exist a considerable relationship, regarding quality and the individual's social networks. Emotional intelligence thus measures the ability to understand oneself, as well as how to relate to others, while directing one's emotions (Goleman, 2013). Therefore, the components of EI which include; self-regulation, self-awareness, empathy and social skills contribute to the outstanding performance in an emotionally intelligent leader. On the contrary, while intelligence quotient (IQ) is important in identifying executives, it is not a predictor of success, but a basic requirement for an executive job (Goleman, 2013).

Emotional intelligence has garnered a lot of interest lately as a construct most sought for in leadership (Stein, Papadogiannis, Yip \& Sitarenios, 2009). Therefore, the EI has been used vastly in assessing individual differences in leadership positions (Hopkins, O'Neil, \& Williams, 2007). Furthermore, EI has been associated with good leadership, with organizational success (Goleman, 1998). EI has been divided into two main models; namely, the ability-based which is cognitive based, and the skill-based EI model which is based on traits. Mayer and Salovey (1990) as cited by Stein, et al. (2009) has defined the EI as "the powers to monitor one's own and others opinions and emotions, to discriminate among them, and to use this information to control thinking" (P. 88). EI therefore, has been linked with leadership because, in the current world, more is needed in leadership other than competences and technical skills (George, 2000), to allow leaders to respond to variant situations in the course of their work (Riggio, et al., 2002). Furthermore, EI have been identified as vital skill in the performance of a high-level leadership, and hence, EI has also been identified as the sine qua non of the headship (Goleman, 2013). Rubin et al. (2005) argued that transformational leadership behaviour is predictable as leaders demonstrate the ability to recognize emotions, sustain positive affect while demonstrating agreeableness. Therefore, there is a positive bond between EI and transformational leadership. Therefore, Transformational leadership often is identified as the most successful leadership style, of which positive organizational performance can be predicted (Northouse, 2016). Transformational leaders are hence emotionally intelligent (Stein, et al., 2009). Furthermore, EI is the hallmark of leadership, without which it becomes impossible to become a leader despite a decisive and an analytical mind-set (Goleman, 2013). Goleman goes on to say that, while the technical skills and the intelligent quotient matter in leadership, the EI plays a vital role in leadership. Emotional intelligence is demonstrated in leadership along the four mechanisms of EI; "self-regulation, self-awareness, empathy, and social skills" (Goleman, 2013, p.66).

\section{PROBLEM STATEMENT}

Leadership happens to be one of the most sought and debated topics, and it has evoked a number of researches. The areas under investigations are competences, attributes in leadership, traits and behaviours and qualities that beget good leadership among others (Parrish, 2011). Therefore, when hiring a leader, the pursuit of an effective leader is a never-ending endeavour. There is increasing evidence one can hold up the payback as well as importance of emotionally intelligent influential and leadership (Parrish, 2011). Consequently, EI has been argued to affect an employee's accomplishment in an organization (Goleman, 2001). In my organization, there is the dearth of researches on EI, and in the overall literature review, there are very few researches on EI in health institutions. The main function of this study is to "To determine emotional intelligence scores in variant levels of nurse leaders." Challenges have been identified in identifying individuals for leadership positions in the recent past. Therefore, identifying the emotional intelligence of the existing leaders would aid in identifying gaps in 
IJCAB

leadership. Similarly, there has not been a research of the similar kind that has been performed in the institution. The study participant are the mid-level managers and team-leaders in nursing leadership positions. The investigator explored the differences in the emotional intelligence scores between the two set groups of nurse leaders; the mid-level managers and the team leaders in nursing leadership.

\section{THEORETICAL FRAMEWORK}

Several researchers thus found there exist a well-built relationship that links emotional intelligence with effectual leadership that equated with positive performance outcomes (Higgs \& Aitken 2003; Rosete \& Ciarrochi, 2005). Because of the varying business, management positions require more than just competences and practical knowledge (George, 2000). Therefore, in order to respond appropriately to the leadership processes, leaders require multiple intelligences among them emotional intelligence (Roggio, Murphy and Pirzolo, 2002)

The Parrish (2011) modified framework was adapted and utilized to depict that effective leadership would be achieved by utilization of EI components in nursing practice culminating to an improved performance.

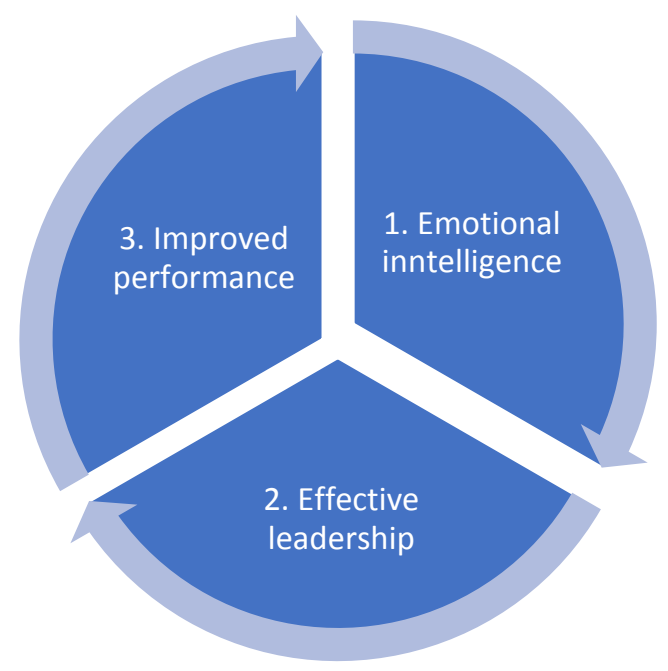

\section{RESEARCH OBJECTIVES}

Overall objective was to identify if there is a difference in the emotional intelligence scores for the mid-level managers and team leaders in nursing

The Specific objectives:

i. To determine the emotional intelligence scores for mid-level managers,

ii. To establish the emotional intelligence scores for team-leaders in nursing,

iii. To determine the differences in the emotional intelligence scores in the two leadership levels

\section{LITERATURE REVIEW}

In human psychology, EI has gained interest and has become a powerful driving force among the general public. All the theories of EI share similar concepts on how individuals identify, embrace, appreciate and manage emotions (Cherniss, 2003). Two models of measuring EI will be discussed; the Goleman model and the Salovey and Mayer models. The Goleman's model measures emotional intelligence using four EI perspectives; which includes, self -awareness, social-management, self-awareness, and social-skills (McEnrue, Groves, and Shen, 2009). The 
elements of emotional intelligence are four mechanisms namely; self-management, empathy, the social skills and self- awareness. These constructs are discussed below. Self-awareness signifies that an individual has a detailed understanding of self, the "emotions, strengths, weaknesses, desires, and the drives" (Goleman, 2013, p. 98). People who are cognizant of who they are, have a realistic approach to life and rarely overcriticize self. The self-aware person is, therefore, able to work with other people in demanding situations, as anger is turned to a constructive scenario (Goleman, 2013). A person who is self-aware is firm and upholds the personal values, while one who has low self-awareness is apt to make decisions which will eventually be regrettable in the future and has no values. The highly aware persons speak with accuracy, are communicates openly. Self-aware people have high level of confidence and a cognizance of when to seek help when the need arises. While having self-awareness is credible, most senior manager give no heed to this component while recruiting potential leaders (Goleman, 2013).

Self-management according to Goleman (2013), is the component in EI that works towards freeing oneself from feelings, bad moods, even in the events of emotional turmoil. Therefore, it is a self-regulating skill, whereby one chooses the reactions to uphold even in obnoxious situations. Self-regulation is therefore valuable in leadership as leaders can control their impulses, are reasonable, and hence gain trust in those they lead (Goleman, 2013). Furthermore, this is associated with improved productivity, while the organizational politics are reduced significantly. The highest level of emotional control is the capacity to effectively handle and normalize emotions which imply the openness to emotional experiences (Cherniss, 2003). Furthermore, the evolution of neuroscience has illuminated the relationship between emotions and pronouncement (Cherniss, 2003). In the current world of competitiveness and diverse changes, self-regulation is equally important, in the advent of change as self-regulated leaders are able to roll out changes seamlessly. Furthermore, self-regulated leaders have a high level of integrity, which not only affects the leader positively but, the organization collectively. This is regarded as an organizational strength and adds to competitive advantage. Such leaders have a high propensity to reflect, are thoughtful and not impulsive in decision making (Goleman, 2013). The self-regulation skill is an intrinsic motivator as it drives the leader to achieve the goals and goes beyond the expectations. Such people exhibit the passion for work, are creative, they seek learning opportunities, and are always yearning to do the work better and forever rising the performance bar (Goleman, 2013). The level of optimisms in these leaders is enormous.

Empathy which is the most easily recognized component of emotional intelligence is, not explicit in those with high intelligent quotient (Goleman, 2013). Empathy entails the ability of a leader to feel other people's sentiments with the aim of building connections with them (Shanker \& Sayeed, 2006). While the word empathy does not conform to the business world, it means taking into consideration the employee's feelings (Goleman, 2013). An example is when a leader acknowledges the followers' fears, and uncertainties in job security, which it is deemed to emphasize empathy. Goleman go on to say that, empathy has been recognized to facilitate team work, useful in the rapid pace of globalization while retaining the follower's talent. This requires coaching and mentoring to retain talents. In this case, a leader who demonstrates empathy feels the presence of all around the table, while taking into account of each followers' viewpoint, ensuring team work. Similarly, when team members are cognizant of the team members' emotions, it facilitates team bonding as they understand each other's needs (Clarke, 2010). Jordan Ashkanasy, Hartel, and Hooper (2002) in their study, identified that, the teams that have higher levels of EI or average emotional intelligence proved to perform better than those with lower levels of EI. Furthermore, EI thus plays a significant role in the formulation of strategy, planning, and goal specification as such roles require the team 
approach (Clarke, 2010). Goleman (2013) concluded that "outstanding coaches and mentors get inside the heads of those they are helping" (p. 229). However, empathetic leaders do not sympathize with their followers but, they use their knowledge to improve them. Empathy in leadership has become pivotal especially with the increasing use of teams, the increase in globalization and the need to retain talents. Because of the emotions that ensue team leading, with the endeavour to hear everyone around the table, the leaders' empathy plays a vital role (Goleman, 2013). This calls for listening to workers one- on-one while directing and understanding each person's emotions as reaching consensus in a group is most often not forthcoming.

Globalization is a key factor which triggers empathy for leaders because when handling crosscultural dialogues, in the absence of empathy, leads to miscommunication in the dialogues (Goleman, 2013). This is because of the cultural and ethical differences especially in multinational companies, where an affirmation in one address may mean the opposite in a different cultural setting. Therefore, the need for retention of talents in an organization is very important, as when experts leave an organization, they leave with the organizational knowledge. Therefore, there is need to utilize the construct of empathy, in order to retain the skills which calls for coaching, mentoring, while nurturing the relationships. While empathy does not get much respect in organizations, empathy is much more than sympathy, but the organizations benefit in subtle ways (Goleman, 2013).

Social skill is a self-management skill which ratifies the ability to manage relationships with other people. This entails friendliness which is directed to a specific purpose. Socially skilled people are viewed to have a wide circle of influence and mingle with all types of people in different social status. These types of leaders have a propensity to build rapport; the social skill is regarded as the culmination of emotional intelligence as such leaders are able to easily control their emotions while handling others and empathize with their feeling (Goleman. 2013). Such leaders are optimistic even in the advent of failure as they are expert persuaders who manifest self-awareness, self-regulation and empathy. Therefore, they are able to discern when to make an emotional plea, are excellent collaborators, and their work is contagious (Goleman, 2013). Most companies consider social skills in leadership when the comparison is made among the other constructs of emotional intelligence. The analogy that leaders are not an island is an affirmation of the importance of social skills in leadership as a leader get things done by influencing others. Therefore, leaders need to communicate their passion for the vision of the organization through social skills. The concept of EI therefore, is no longer a nice to have, but an imperative. This is because several studies have shown work related outcomes with higher EI. The competency approach-based measure used by Joseph and Newman, (2010) and O'Boyle et al., (2011) identified that employees with higher scores in EI, were rated to be better performers. EI, however, can be learned, and therefore, it is worth the effort to teach it because the benefits that come with it are valuable in the organization (Goleman, 2013).

The ability model is another model of EI which was coined by Salovey and Mayer (1990), as cited by Clarke (2010). Salovey and Mayer (1990) defined the EI construct more narrowly with four cognitive abilities linked with emotional information processing. The cognitive capabilities include; "perceiving emotions using emotions, understanding emotions and controlling emotions in self and others" Clarke (2010, p. 8). Subsequently, this model has been used and found to have empirical evidence in incremental validity and is independent of the personality construct. The EI skills that the employers are seeking include people who work well with teams, leaders who can effectively communicate, who can adapt well to change, and can interact widely, and are able to solve problems under pressure (Goleman, 2013). The effects of EI in leadership to the follower plays a significant role in leadership. The follower mirrors 
the leader at work. There are dispersed mirror neurons in the brain that were discovered by an Italian neuroscience accidentally. Goleman (2013) says that, when someone reluctantly detects another's emotions through their deeds, the mirror neurons will replicate those emotions. In that case, the leader emotions and actions likewise will prompt the supporters to mirror the same feelings and actions. Therefore, if a leader makes the followers feel better their performance will be improved (Goleman, 2013). Hopkins, O'Neil, and Williams (2007), in their study, found out that, EI construct is vital in leadership along the domains of decision making, team work, exercising authority, and acting strategically. Clarke (2010) argues that EI abilities and team work and effectiveness of teams have been theoretically associated, while conflict management and cooperation poses significant emotion dimensions.

Similarly, Wolff et al., (2006) identified trust and commitment to have EI as the genesis at development. In essence, the team members that are good at controlling their emotions are said to be motivating while helping their teams to resolve conflicts (Prati, et al., 2003). Similarly, individuals who have higher than average EI, performed better at work and had statistical significance conflict resolution. While intelligent quotient (IQ) is vital in identifying people's cognitive complexities in career choice, emotional intelligence is twice as important when compared with IQ in achieving excellent performance (Goleman, 2013). Therefore, among the highly intelligent people, and outstanding leaders, EI takes the lead in achieving exemplary productivity. Similarly, EI has been associated with organizational outcomes, and the expectations is that, there is a relationship between the businesses perceptions in staff who have a high EI score (Stein, Papadogiannis, Yip \& Sitarenios, 2009). Also, the assumption is that those with high scores will yield higher profits in business. This would be tested by measuring EI which is performed in variant methods to achieve a comprehensive assessment. The methods of measuring EI will be discussed below.

EI is measured based on the whether a person is aware of their feeling's existence and the reason behind the feelings, the ability of the leader to manage his distressing situations as well as cognizance of one's limitations and strengths. The ability to adapt to changes in situations, considering the emotions of other people while keeping focus to the main goals, and the capability to persuade, and deal with conflicts is pivotal (Goleman, 2013). To assess the social intelligence of a leader, four constructs are taken into consideration, empathy, organizational awareness, influence, developing others and inspiration. Empathy is the understanding of other people's motives is key while having the sensitivity to other's need. Organizational awareness refers to appreciation of the cultures and values of those working in the organization and being cognizant of social networks and know the unspoken word. Influence; the ability to persuade and getting support from the teams. Developing others is the ability to coach and mentor others with high levels of compassion, while providing constructive feedback. Inspiration is the ability to articulate a compelling vision while fostering positive motivation within the group in an organization, at the same time identifying the best talent required in the organization (Goleman 2013). Therefore, EI has been associated with performance at work, and transformational leadership (Mandell and Pherwani, 2003). This is because leadership behaviour can arouse a whole range of emotions to include optimism, joy, anger and frustration which in turn influences the followers' behaviour (Li, Gupta, Loon, \& Casimir, 2016).

There are several scales that measure EI some in the form of EI questionnaires, while others look at EI as a multi-dimensional construct. Some are simplistic with multiple items indexing for EI measurement as a unidimensional construct (Shanker \& Sayeed, 2006). One of the scales used is a five-dimensional trait -based model coined by Bar-On's in 1997, consisting of interpersonal, stress management, intrapersonal, adaptation and general mood factors (McEnrue, Groves, \& Shen, 2009). The Bar-On scale is scientifically validated for assessing 
II $J$ CAB

EI of the respondents. It was derived from a 15 subscales measures such as "Assertiveness, Empathy, Problem Solving, Social Responsibility, Optimism, Self-Awareness, and Reality Testing" (Shanker \& Sayeed, 2006). The sole purpose of this test is to measure the build-up of EI and its efficacy while predicting predefined outcome measures for the purse of using the tool to do individual EI assessments. Another scale used is the Emotional Competence Inventory (ECI) developed by Goleman, and colleagues, which assess the competencies and communal behaviour (Goleman, 2013). The ECI comprises of 110 items assessing 20 capabilities compressed to four competencies; Self-Management, Social Skills and SelfAwareness, which measures a holistic view of EI, through self and peer rating using the 360review approach. The ECI is "supported by strength evidence from the Self-Assessment Questionnaire (SAQ), which is an antecedent of the ECI" (Conte, 2005, p.433). However, the ECI is said to have not provided the discriminate and predictive validity evidence.

Another model is a seven-dimensional trait-based model coined by Dulewicz and Higgs (2000), which comprises of self-awareness, motivation, influence, interpersonal compassion, emotional flexibility, intuitiveness, and attention to detail. Another major EI theoretical outlook was coined by Salovey and Mayer' in the 1990's, a four-dimensional model that comprises of emotional awareness, assessment, expression and emotional facilitative thinking (McEnrue, Groves, \& Shen, 2009).

Generally, the available El measures have confirmed acceptable internal consistency reliability. Because the tools are self-reporting measures of El, they have an acceptable internal consistency measure (Conte, 2005, p.433). Furthermore, all the models above are utilized to deal effectively with emotions. Emotions have a link to life outcomes of individuals which will be discussed below. Several researchers have identified a significant correlation between EI and significant life outcomes to include mental health (Cherniss, Roche, Barbarasch \& Friedman, 2016). Brackett et al. (2011) found that individuals who highly score on EI had lower scores in depression, anxiety and drug abuse among other mental health problems. EI has been empirically linked with social functioning (Cherniss, Roche, Barbarasch \& Friedman, 2016), while higher EI was linked with loyal relationships, while the lower EI was related with conflicting relationships (Lopes et l., 2005). However, three competences of emotional quotient (EQ) have been identified which complement each other in leadership; intellectual (IQ), emotional (EQ), and managerial (MQ). While EQ is linked with success, the MQ competence is associated with managing resources which impact on the perception of success to the many stakeholders, while strategic perspective (an IQ competence) influences the organizational achievement measures of time, cost, and quality (Dulewicz and Higgs, 2000). These competences are deduced from 15 components; "Self-regard, Emotional Self-awareness, Independence, Assertiveness, Self-actualization, Interpersonal EQ, Empathy, Interpersonal Relationship, social responsibility, Stress Management EQ, Stress Tolerance Impulse Control, Adaptability EQ, Flexibility, General Mood EQ, Optimism, Problem Solving, bonding and team work collaboration" (Chang, 2007, pp. 28-29).

Because emotional intelligence is a subset of self- leadership, there is a related construct that propagates self-leadership an example is self-efficacy. Self- efficacy is the self-confidence that a leader has that, as one has what it takes to succeed (Bandura, 1999). Similarly, leaders who possess self-efficacy are able to regulate their emotions and require regular positive self-talks, which is a self-regulatory management process (Rogelberg, et al., 2013). Therefore, constructive self-talk has a direct influence in leading others. Clarke (2010) denotes that, individuals who belief they are capable of enhancing EI have high levels of self-efficacy. Leaders need to foster a profound knowledge of who they are to be effective leaders (Karp, 2012). Another concept related to EI is locus of control which is a self- leadership construct. 
Internal locus of control denotes that, individuals themselves are in control of their outcomes rather than external factors like their supervisors, while those with external locus of control belief that, external factors like fate, chance, or luck control their outcomes (Chen and Silverthorne, 2008). Furthermore, Chen, Li, and Leung (2016) argues that, internal locus of control and self-efficacy are related as both concepts resonate an optimistic belief about individual control over achievement. They are positively interrelated and show positive effects on various required outcomes (Judge, Erez, Bono, \& Thoresen, 2003). Naturally motivated employees have a high level of cognitive flexibility, are persistence and innovative (McGraw \& Fiala, 1982). Those with internal locus of control are emotionally intelligent. Emotional intelligence plays an important role and is often misunderstood or an unrecognized element in the career management process. While emotional intelligence has garnered interest in leadership and has been regarded as the hall mark for leadership, it has not gone uncriticised.

EI may be used to influence others for personal gains as opposed to the gains for the organization (Goleman, 2013). The concept of 'intelligence' involves abilities related to conceptual reasoning, the processing of information and problem-solving; EI can therefore be thought of as a type of intelligence that involves processing of information and reasoning emotions in order to accomplish one's goals (Cherniss, Roche, Barbarasch \& Friedman, 2016). While EI is an essential construct in leadership, the critique of EI indicates that EI is correlated with personality measures and therefore not easily differentiated from personality concepts (Hopkins, O’Neil \& Williams, 2007). However, the proponents of EI claim that there is enough empirical evidence, that shows a distinction between EI and personality constructs as demonstrated by Cherniss et al. (2006) as cited by Hopkins, O’Neil, and Williams (2007).

\section{METHODOLOGY}

The study seeks the differences in the EI scores between the team leaders and the mid-level managers in nursing. In this study, I used the Emotionally Intelligence Leadership tool for students Inventory (EIL) facet to measure the EI scores against nineteen capacities that supply individuals with the skills, knowledge, attitudes and perspectives to attain the leadership outcomes (Shankman, Allen, \& Miguel, 2015). The variables measured are emotional selfcontrol, emotional self-perception, healthy self-esteem, authenticity, displaying empathy, flexibility, initiative, optimism, achievement, coaching, inspiring others, demonstrating citizenship, capitalizing on differences, building teams, facilitating change, analysing group, developing relationships, managing conflict and assessing the environments. The nineteen constructs are then grouped to three facets of EI; realization of self which is self-awareness, the consciousness of others meaning influencing and engaging others, and the consciousness of the context which means what works in an instance will not work in another situation (Shankman, Allen, \& Miguel, 2015). The dependent or the outcome variable in this study is a level of leadership i.e. the mid-level manager or team leader which determines the score of EIL which is the independent variable in any of the three facets of EI. The question is "Do the level of leadership influence the EIL score?"

A quantitative design was used. A quantitative design is used for deductive reasoning and generates predictions. The data gathered is quantitative and the numeric information gathered is analysed statistically (Polit \& Beck, 2012). A correlational method was used, whereby two groups of nurse leaders' emotional intelligence leadership (EIL) scores were compared. That is the mid-level managers and the team leaders (dependent variables) ELI scores (independent variables). Therefore, because it is not possible to manipulate the independent variable, the study is non-experimental. Correlation studies looks at the relationship or the association between two variables, however, it is difficult to infer causal relationship in this study (Polit \& Beck, 2012). The population of the study was drawn from nurse leaders in a private city hospital 
IJCAB

in Nairobi. The total population $(\mathrm{N})$ of nurses is 620 nurses in the private city hospital, and the nurse leaders (n) are 45 nurses at different leadership positions. The population of interest is the mid-level managers who are 20 in number and the team leaders who are 20 also, while others five leaders are the directors and the assistant director. Due to the nature of the study; academia and the limited time to carry out the study, a verbal consent was obtained from the leaders in a meeting, and there was and unanimous agreement, after ascertaining confidentiality and the right to opt out of the study involvement.

Inclusion criteria- All mid-level managers and the team leaders on duty on the day of data collection. Exclusion criteria- The nurses who are not in the leadership positions and the directors and the assistant directors of nursing services. The mid-level managers and the team leaders who were on leave. Because of the low number of the target population, which was below fifty (50), all the members of the target groups who fitted in the inclusion criteria participated in the study. The sample, therefore, is a representation of the target population. The sampling plan was therefore nonprobability, and therefore, convenient sampling was used because all the population that fitted the sampling criteria were studied.

The study setting was a private city hospital in Nairobi, in the Nairobi County, and the study was performed on two levels of nurse leaders. The purpose of the study was to identify the degree to which the level of leadership either team leadership or mid-level managers in nursing leadership influences the EIL scores. Two groups of nurse leaders; the mid-level managers and the team leaders were enlisted to complete the EIL inventory. The team leaders in the hospital setting report to the mid-level manager, and occasionally perform leadership roles in the absence of the mid-level managers. All members were guaranteed anonymity by not indicating their names on the data collection tool, the departments they worked in, their age and length of employment. This was done intentionally because the sample size was small comprising of 18 mid-level managers and 18 team leaders, and all the leaders are well known to the author.

Emotional intellect was measured using emotional intelligence leadership inventory (EIL) which is a self-reporting tool attached as appendix I. EIL was measured against a fifty-seven (57) EI self-reporting seven scale questionnaire. The level of EI score, indicating the extent to which how the statement applied to the responder were distributed in the seven scales as follows; 1- never, 2- almost never, 3- rarely, 4-sometimes, 5-usually, 6- almost always and 7always. The scores ratings were then transferred to corresponding facets of EIL which was compressed to nineteen different groups of constructs attached as appendix II. The constructs included; emotional self-control, emotional self-perception, well-being self-esteem, optimism, empathy, authenticity, initiative, achievement, coaching others, flexibility, inspiring others, capitalizing in differences, building teams and developing relationships, demonstrating citizenship, facilitating change, analysing group, managing conflicts, and assessing the environment. The researcher attempted to match the two levels of leadership against their scores on the different facets of EI.

Data was collected with an Emotional Intelligence Leadership for student (EIL) inventory, a self-administered tool adopted from (Shankman, Allen, \& Miguel, 2015). Research using a quantitative approach is conducted to describe new situations, while examining relationships among concepts or ideas. The questionnaire is rated into seven-point scale as described earlier. A Higher emotional control is represented by a higher score, while the lower will indicate a lower score of emotional intelligence. Several types of researches have been performed using the EQ-i to determine the EI construct legitimacy and have exhibited meaningful patterns of convergent legitimacy (Dawda \& Hart, 2000). The EQ-i is a self-report assessment skill-based model used for leadership (Stein, Papadogiannis, Yip, \& Sitarenios, 2009). While the EIL inventory tool used is for analysing student leadership, the constructs of measure for leadership 
apply across leadership at all facets, and it is similar to the EQ-i. The EQ-i has been used in several types of research to determine to construct authority and has demonstrated a meaningful patter (Stein, et al., 2009). Construct validity is the level to which an apparatus measures the construct under study (Polit \& Beck, 2012). Similarly, the EI measures have been found to demonstrate adequate internal consistency and reliability (Conte, 2005). Internal reliability refers to the "degree of consistency or steadiness with which an instrument measures an attribute" (Polit \& Beck, 2012, p. 741). Therefore, the self-report EI measures have been reported to have internal consistency, while content validity in EI measures lacks. Content validity refers to "degree to which items in the instrument sufficiently represent the universe of the content for the concept being considered" (Polit \& beck, 2012, p. 723).

\section{STUDY FINDINGS}

The initial data were analysed in an excel sheet and thereafter in SPSS program. The EI scores were analysed for each facet of EI for the different groups of nurse leaders; the mid-level managers and the team leaders. The differences in EI scores and the standard deviation of the different population under study were identified. Standard deviation was calculated to measure the degree of inconsistency in the set of scores (Polit \& Beck, 2012). The comprehensive EI scores were calculated for each group, and the standard deviations was calculated for all facets of EI. The standard deviation between the team leaders and mid-level nurses was 0.945582468 , meaning that there is a small difference between the two categories. The EIL facets standard deviation are varies ranging from 0.7 to 15 . The mid-level managers indicate a higher EIL compared to the team leaders.

The table 1 below shows each statement of the EIL results, the differences and the deviation between the two categories; the team leaders and mid-level managers.

Table 1: EIL Results

\begin{tabular}{|l|c|c|c|c|}
\hline Statement & $\begin{array}{c}\text { Mid-level } \\
\text { Managers }\end{array}$ & $\begin{array}{c}\text { Team } \\
\text { Leaders }\end{array}$ & $\begin{array}{c}\text { Differenc } \\
\text { e }\end{array}$ & Standard Dev. \\
\hline $\begin{array}{l}\text { Emotional self-perception } \\
\text { (ESP) }\end{array}$ & 298 & 288 & 10 & 7.071067812 \\
\hline Emotional self-control (ESC) & 279 & 282 & -3 & 2.121320344 \\
\hline Authenticity (AU) & 316 & 313 & 3 & 2.121320344 \\
\hline Healthy self-esteem (HSE) & 315 & 296 & 19 & 13.43502884 \\
\hline Flexibility (FL) & 310 & 256 & 54 & 38.18376618 \\
\hline Optimism (OP) & 321 & 296 & 25 & 17.67766953 \\
\hline Initiative (IN) & 302 & 307 & -5 & 3.535533906 \\
\hline Achievement (AC) & 309 & 287 & 22 & 15.55634919 \\
\hline Displaying empathy (DE) & 299 & 302 & -3 & 2.121320344 \\
\hline Inspiring others (IO) & 319 & 287 & 32 & 22.627417 \\
\hline Coaching others (CO) & 322 & 302 & 20 & 14.14213562 \\
\hline
\end{tabular}


International Journal of Current Aspects, Volume 3, Issue III, 2019, PP 41-57, ISSN 2616-6976 [IJCAB

\begin{tabular}{|l|c|c|c|c|}
\hline \hline $\begin{array}{l}\text { Capitalizing on differences } \\
\text { (CD) }\end{array}$ & 311 & 287 & 24 & 16.97056275 \\
\hline Developing relationship (DR) & 304 & 290 & 14 & 9.899494937 \\
\hline Building teams (BT) & 320 & 303 & 17 & 12.02081528 \\
\hline $\begin{array}{l}\text { Demonstrating citizenship } \\
\text { (DC) }\end{array}$ & 307 & 297 & 10 & 7.071067812 \\
\hline Managing conflict (MC) & 305 & 271 & 34 & 24.04163056 \\
\hline Facilitating change (FC)p & 293 & 294 & -1 & 0.707106781 \\
\hline Analyzing the group (AG) & 288 & 284 & 4 & 2.828427125 \\
\hline Assessing environment (AE) & 303 & 291 & 12 & 8.485281374 \\
\hline
\end{tabular}

The correlation coefficient of the two intended variables is 0.25711 which measures the potency and direction of the association of a linear association between the two categories. This means that between the variable measured, there is a weak positive correlation. Regardless of that weak relationship, the variables are directly proportional whereby when the scores for team leaders' increase so does the scores for the mid-level managers. Comparing the EIL scores between the mid-level managers and the team leaders indicate that, in consciousness, to self on the emotional self-perception the midlevel managers scored higher than the team leaders with a standard deviation of 7.1. The mid-level managers demonstrated a significantly higher health self-esteem compared with the team leaders with a standard deviation of 13.4. The highest difference was demonstrated in flexibility where the mid-level managers illustrated to be more flexible than the team leaders with a standard deviation of 38.2. The mid-level managers demonstrated more optimism compared to the team leaders as demonstrated by a standard deviation of 17.7. The mid-level managers demonstrated higher EIL compared to the team leaders as demonstrated by a standard deviation of 15.5. However, the team leaders demonstrated a higher EIL in emotional self-control compared to the mid-level managers. Similarly, the team leaders illustrated higher ELI in initiative compared to the mid-level managers with a standard deviation of 3.5.

When comparisons were made on the construct of consciousness to others, the team leaders displayed empathy more than the mid-level managers demonstrated with a standard deviation of 2.1. Similarly, the team leaders demonstrated higher EIL in facilitating change compared to the mid-level managers. The mid-level managers scored highly than the team leaders team leaders in the following facet; inspiring with a standard deviation of 22.6, building teams with a standard deviation of 12 , coaching others with a standard deviation of 14.1, capitalizing on the differences with a standard deviation of 16.9, developing relationships, with a standard deviation of 9.9, building teams, standard deviation of 12.0, demonstrating citizenship, standard deviation of 7.1, and managing conflict with standard deviation of 24.0. When the facet of consciousness to context was analysed on the two elements; the mid-level managers demonstrated higher ELI scores in both the construct of analysing the group and assessing environment when compared with the team leaders with the standard deviation of 2.8 and 8.5 respectively.

The EIL scores were then plotted on the chart below and were compressed further to three constructs indicating; consciousness of others, of self and that of the context. To note, the chart indicates the EIL constructs from emotional self-perception, to the achievements denotes consciousness to self (ESP-AC), while the constructs from displaying empathy to facilitating 
change (DE-FC), denotes consciousness to others while the constructs from analysing the group to assessing the environment (AG-AE) indicates consciousness to context. While the EIL scores are different figuratively, the pattern of the scores is similar for both the middle level managers and the team leaders. The mid-level managers demonstrate high scores in consciousness to self with exception of one element in emotional self-control, while the team leaders have a similar pattern with the exception of flexibility. The consciousness to others patterns is similar with the exception of the team leaders' flexibility to change which is lower. The construct of consciousness to cortex have a similar pattern for the two groups of leaders; the team leaders and the mid-level managers. Below are the ELI scores plotted on the graphs to illustrate the pattern on the three constructs of EIL?

Key: Consciousness to self- ESP-AC; Consciousness to others-DE-FC; Consciousness to context- AG-AE.

\section{Figure 1: Mid-level Managers EIL Scores}

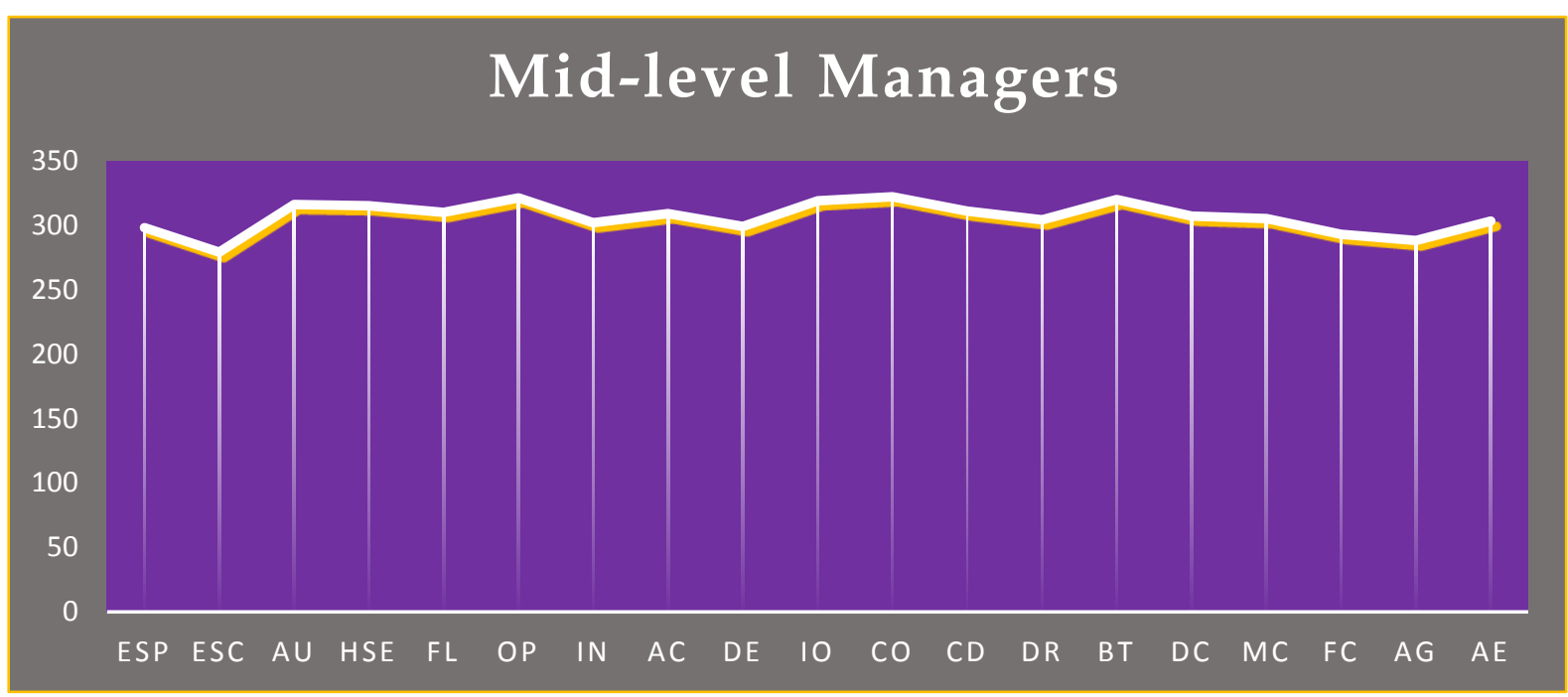

The graph 2 below illustrates the team-leaders' EIL scores

\section{Figure 2: Team Leaders EIL Scores}

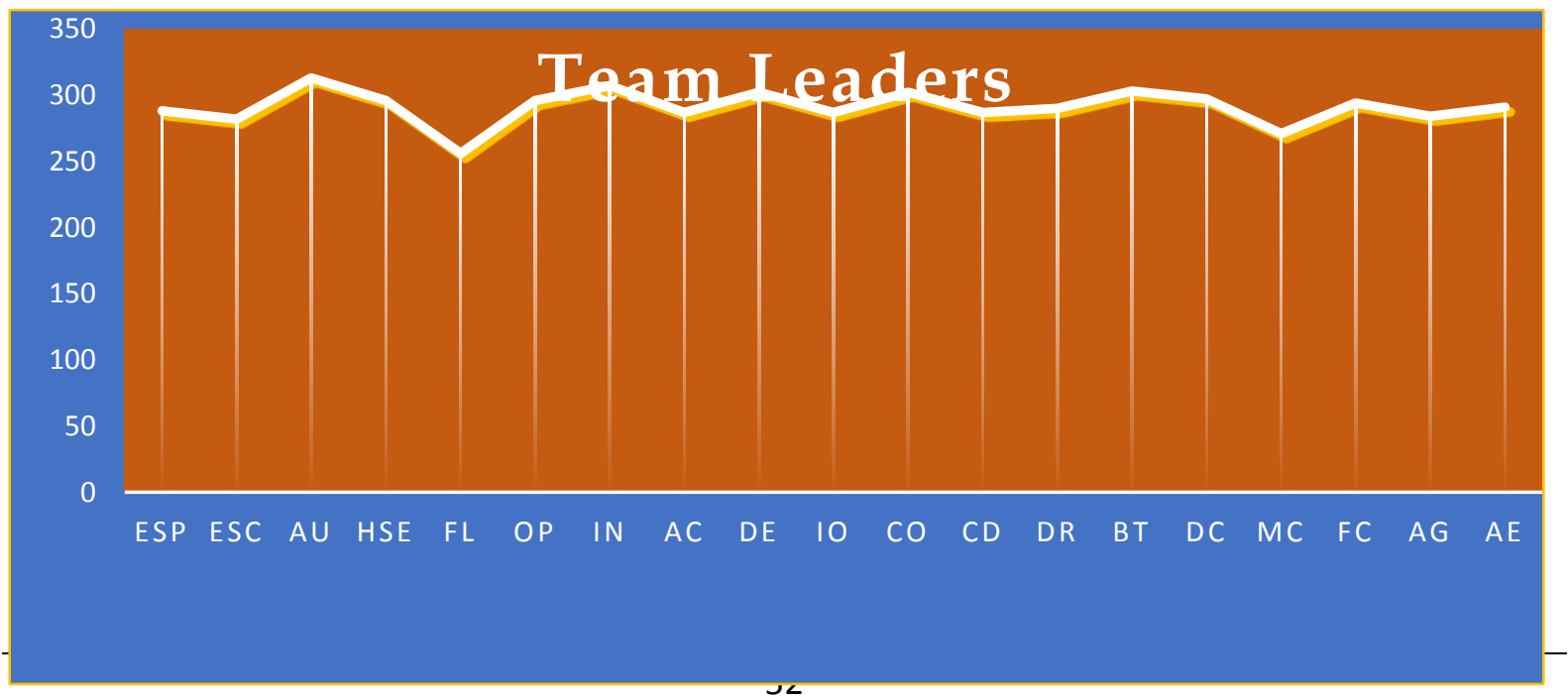


The EIL scores are significantly high for both the team leaders and the mid-level managers, however with differences in various aspects in EIL. There is therefore empirical evidence that mid-level managers have higher EIL than the team leaders who are junior. This is supported by Rosete and Ciarrochi (2005) who found a positive association of higher emotional intelligence scores and the higher leadership and usefulness in leadership. The higher EI scores also explained variances that could not be explained by the intelligence quotient. In this study, the mid-level managers demonstrated higher EIL scores on the consciousness to self, which denotes that, emotionally intelligence leaders are self-aware of their abilities, emotions, and perceptions (Shankman, Allen, \& Miguel, 2015). Furthermore, an emotionally intelligent leader demonstrates consciousness in reflection and introspection, which is an ongoing process in leadership. The mid-level managers demonstrated the highest score in flexibility with a standard deviation of 13.1 and managing conflict with a standard deviation of 24.0 when compared to the team leaders. This can be correlated with the findings of Stein, et al., (2009) who reported higher EI scores for the top executives in flexibility, and problem-solving. Both of the composites would denote the top leaders can survive in organizations longer and are able to adjust to situations that call for emotional intelligence in and tailor solutions for problems. Furthermore, leaders who are effective problem solvers, are associated with higher profits. Effective management of conflict in leadership provides the leader with the skill to move the organization beyond the interest of individuals (Hopkins, O’Neil \& Williams, 2007).

The analysis for optimism scored higher in the mid-level managers compared to the team leaders with a standard deviation of 17.7. When Stein, Papadogiannis, Yip, and Sitarenios (2009), compared the confidence of executives with the general population, they found that optimism and stress tolerance scored higher indicating that, in order to empower an organization, it is imperative for leaders to maintain a calm and a positive attitude in adversities. The concepts of coaching and inspiring others, the mid-level managers, scored higher than the team leaders with the benchmarked deviations of 16.9 and 14.1 respectively. This would denote that, the mid-level managers are aware of their own emotions and those that they lead, and by so doing, the staff retention, motivation, and dedication are maintained (Stein, Papadogiannis, Yip \& Sitarenios, 2009). This has an effect on the organizational bottom line. The analysis on facilitating change took a different direction, where the team leaders scored more than the midlevel managers, with a standard deviation of 0.71 . While flexibility had the highest score for the mid-level managers, it plays a big role in managing change as the mid-level managers are the implementers of change.

The concept of empathy indicates that the team leaders demonstrated to be more empathetic compared to the mid-level managers with a standard deviation of 2.1. Effective leaders display empathetic behaviour while demonstrating how others feel. This is meant to fortify the relationships at work while unifying team (Ashkanasy \& Tse, 2000). When the concept of building teams was analysed, the mid-level managers demonstrated higher level compared to the team leaders with a standard deviation of 12.0. Similarly, Clarke (2010) reported an affirmative relationship connecting emotional intelligence and team work. Consequently, the motivation of the people might influence the team processes, as well as cooperative behaviour. Furthermore, team effectiveness was positively associated with high scores of EI. In line with this, keeping teams informed and, offering support, encouraging teams is dependent on the use of emotional intelligence. Hopkins, O’Neil and Williams (2007) demonstrated a robust bond between high scores of EI and effective leadership, and transparency, team work and collaboration. Subsequently, transparency builds trust which leads to a better working climate which enhances job satisfaction. 
II $J$ CAB

The healthy self-esteem concept when analyzed, the mid-level managers demonstrated a higher score of self-esteem when compared with the team leaders with a standard deviation of 13.4. The demonstration of confidence in emotionally intelligent individuals is by exercising authority (Hopkins, O'Neil \& Williams, 2007). A self-confidence leader is decisive and action oriented. Therefore, effective leaders must be confident and exercise authority. Developing others is another characteristic of EI. Leaders who are coaches have excellent communication skills. The mid-level managers score significantly higher in coaching compared to the team leaders with a standard deviation of 14.1. Similarly, Hopkins, O'Neil and Williams (2007) found that developing others, coupled with coaching and mentoring was associated with high levels of EI. Therefore, emotionally intelligent leaders sense the need for others growth and identifying opportunities for individual and team enhancement.

The need for achievement is a concept of EI which when analysed demonstrated that the midlevel managers had higher EIL scores compared to the team leaders with a standard deviation of 15.5. Achievement and initiative, require the leader to plan, organize and evaluate policies while setting the standards for the organization (Hopkins, O'Neil \& Williams, 2007). The achievement concept and initiative go hand in hand and entails being proactive and futuristic in ideas. The scores demonstrated that the team leaders were more futuristic than the mid-level managers with a standard deviation of 3.5 in the initiative. Therefore, the team leaders have the potential to anticipate issues, design a vision for the future. One of the findings that was unexpected was the emotional self-control concept and facilitating change whereby the team leaders scored higher than the mid-level managers with a standard deviation of 2.1 and 0.7 respectfully. However, a similar finding was demonstrated by Hopkins, O'Neil and Williams (2007), in their study on identifying the EI concepts in the board of governors in school leadership. They found out that, the board of governors who can be equated to the mid-level managers in this case, that they lacked self-awareness, change catalyst competency and optimism. The concept of self-control which is a subset of self-awareness, measures the individual judgment and situations evoking strong reactions in an individual. The absence of change catalyst competency, was rather unexpected, as it provides strategic directions in organizational vision shaping (Hopkins, O’Neil \&Williams, 2007).

Stein, Papadogiannis, Yip and Sitarenios (2009) performed a study comparing two groups of leaders; executive and the general population. The premise was that transformational leadership requires a leader to be positive, in their capacity to deal with their own emotions and the emotions of others. Similarly, most studies that evaluate relationships of leadership and EI often relate to transformational leadership conduct. Transformational behaviour has drawn a positive relationship with EI which involve captivating vision while providing individualized intellectual support (Harms \& Crede, 2010). Consequently, El has been recognized as the antecedent for transformational leadership behaviour. On the same vein, EI has been shown to be linked with ethics. Therefore, emotionally intelligent leaders have a propensity of behaving ethically, establish caring interpersonal relationships while acting within emotional expectations (Walter, Cole \& Humphrey, 2011). In this case, application of EI in leadership is an imperative. Many studies have indicated that individuals can be trained in EI. My endeavour is to train EI in the different leadership levels in nursing in conjunction with transformational leadership.

\section{CONCLUSION}

EI intelligence is indeed the sine qua non for headship. EI encompasses a whole spectrum of emotional management right from the leader and the community and the environment. In this study, I have identified that emotional intelligence can be measured in different tools and one tool alone does not measure the concepts of emotional intelligence comprehensively. I 
identified that emotional intelligence in senior people in leadership positions is higher than those in lower leadership positions. However, one unexpected finding was the lower EI was observed in the concepts of emotional self-control and the facilitating change. This was unexpected because the mid-level managers are the implementers of change in the organization. This was not associated with any other factor under study. One more unexpected finding was on initiative and display of empathy. Therefore, decision makers require to include the EI competencies as a requirement when recruiting individuals in leadership positions.

\section{RECOMMENDATIONS}

I would recommend further study on EI using combination of different tools to get comprehensive responses on the different facets of EI, and triangulation of data collection to have a rich data to inform the real state of EI in leadership. The outcomes of the EI application should be explored in relation to other constructs like performance and employees' retention. Further recommendations would be training leadership on EI. This will yield benefits not only to the individual but the organization in totality.

\section{REFERENCES}

Ashkanasy, N. M. and Tse, B. (2000). Transformational leadership as management of emotion: a conceptual review, in Ashkanasy, N. M. Hartel, C. E. J. and Zerbe, W. J. (Eds.), Emotions in the work place: Research, Theory, and Practice, West port: Quortum Books, pp. 221-235.

Austin, E. J., Farrelly, D., Black, C., \& Moore, H. (2007). Emotional intelligence,

Machiavellianism and emotional manipulation: Does EI have a dark side? Personality and Individual Differences, 43, 179-189.

Austin, E.J., (2010). Measurement of ability emotional intelligence: Results for two

New tests. British Journal of Psychology, 101, 563-578.

Bandura, A. (1999). Self-Efficacy in changing societies. Cambridge: Cambridge University Press.

Brackett, M.A., Rivers, S.E., Salovey, P., (2011). Emotional intelligence: Implications for personal, social, academic, and workplace success. Social and Personality Psychology Compass, 5 (1), 88-103.

Chang, K. B. T. (2007). Can we teach emotional intelligence? Dissertation Abstracts International Section A: Humanities and Social Sciences, 67(1 2- 4451.

Chen, J. C. and Silverthorne, C. (2008). The impact of locus of control on job stress, job performance and Job satisfaction in Taiwan. Leadership and Organizational Journal, 29(7)2008.

Chen, T., Li, F., \& Leung, K. (2016). When does supervisors support, encourage innovative behaviour? Opposite moderating effects of general self-efficacy and internal locus of control. Personnel Psychology, 69, 123-158.

Cherniss, C., Extein, M., Goleman, D. and Weissberg, R.P. (2006). Emotional intelligence: what does the research really indicate? Educational Psychologist, 41 (4), 239-45.

Cherniss C., Roche C., and Barbarasch B. (2016). Emotional Intelligence. In: Howard S.

Friedman (Editor in Chief), Encyclopaedia of Mental Health, 2, Waltham, MA: Academic Press, 2016, 108-115.

Clarke, N. (2010). Emotional intelligence abilities and their relationships with team processes. Team Performance Management, 16, (1/2), 6-32.

Conte, J. M. (2005). A review and critique of emotional intelligence Measures. Journal of Organizational Behaviour, 26, (4), 433-440. 
Dawda, D. and Hart, S.D. (2000), "Assessing emotional intelligence: reliability and validity of the Bar-On Emotional Quotient Inventory (EQ-i) in university students" Personality and Individual Differences, 28, 797-812.

Dulewicz, V., \& Higgs, M. (2000). Emotional intelligence: A review and evaluation study.Journal of Managerial Psychology, 15, 341-372.

George, J.M. (2000), "Emotions and leadership: the role of emotional intelligence", Human Relations, 53(8), 1027-1055.

Goleman, D. (1995). Emotional Intelligence, Bantam, New York, NY.

Goleman, D. (1998). Working with Emotional Intelligence. Toronto: Bantam Books. Goleman, D. (1998b). Emotional Intelligence: Why It Can Matter More than IQ, Bantam Books. New York, NY (originally published in 1995).

Goleman, D. (2001). "An EI-based theory of performance", in Cherniss, C. and Goleman, D. (Eds), the Emotionally Intelligent Workplace. San Francisco: Jossey-Bass, CA, 27-44.

Goleman, D. (2013). What makes a Leader: Why Emotional intelligence matters? LLC Florence, MA: More than sound.

Harms, P. D., \& Crede, M. (2010). Emotional intelligence and transformational and Transactional leadership: A meta-analysis. Journal of Leadership \& Organizational Studies, 17, 5-17.

Higgs, M, \& Aitken, P. (2003). An exploration of the relationship between emotional intelligence and leadership potential. Journal of Managerial Psychology, 18, (8), 814823.

Hopkins, M. M. O'Neil, D. A. and Williams, H. W. (2007). Emotional intelligence and board governance: leadership lessons from the public sector. Journal of Managerial Psychology, 22 (7), 683-700.

Jordan, P.J., Ashkanasy, N.M., Hartel, C.E.J. and Hooper, G.S. (2002). Workgroup emotional intelligence scale development and relationship to team process effectiveness and goal focus. Human Resource Management Review, 12, (2),195-214.

Joseph, D.L., Newman, D.A., (2010). Emotional intelligence: An integrative meta-analysis and cascading model. Journal of Applied Psychology, 95, 54-78.

Judge TA, Erez A, Bono JE, Thoresen C. J. (2003). The core self-evaluations scale: Development of a measure. Personnel Psychology, 56, 303-331.

Karp, T. (2013). Developing oneself as a leader. Journal of management development, 32(1), 127-140.

Lopes, P. N., Salovey, P., Crtd, S., \& Beers, M. (2005). Emotion regulation ability and the quality of social interaction. Emotion, 5(1), 113.

Mandell, B., \& Pherwani, S. (2003). Relationship between emotional intelligence and transformational leadership style: A gender comparison. Journal of Business and Psychology, 17, 387-404.

Mayer, J.D. and Salovey, P. (1997). "What is emotional intelligence?" in Salovey, P. and Sluyter, D.J. (Eds), Emotional Development and Emotional Intelligence:Educational Implications Basic Books, New York, NY.

Mayer, J. and Salovey, P. (1990). "Emotional intelligence", Imagination, Cognition and Personality, 9 (3), 185-211.

McEnrue, M. P., Groves, K., S. and Shen, W. (2009). Emotional Intelligence development: Leveraging individual characteristics. Journal of management Development, 28, (2), $150-174$.

McGraw KO, Fiala J. (1982). Undermining the Zeigarnik effect: Another hidden cost of Reward. Journal of Personality, 50, 58-66. 
O’Boyle Jr., E.H., Humphrey, R.H., Pollack, J.M., Hawver, T.H., Story, P.A., (2011). The relation between emotional intelligence and job performance: A meta-analysis. Journal of Organizational Behaviour, 32, 788-818.

Parrish, D. (2011). Developing Emotionally Intelligent Leadership in Higher Education. Bern: Peter Lang A. G., International Academic Publishers.

Polit, D. F and Beck, C. T. (2012). Nursing research: Generating and Assessing evidence for nursing research. Philadelphia: Wolters Kluwer/Lippincott Williams and Wilkins.

Prati, L.M., Douglas, C., Ferris, G.R., Ammeter, A.P. and Buckley, M.R. (2003). Emotional intelligence, leadership effectiveness, and team outcomes. International Journal of Organisational Analysis, 11(1), 21-40.

Rogelberg, et al. (2013). The executive mind: leader self-talk, effectiveness and strain. Journal of managerial psychology, 28, (2), 183-201.

Roggio, R.E., Murphy, S.E. and Pirzolo, F.J. (2002). Multiple Intelligences and Leadership. Mahwah, NJ: Lawrence Erlbaum Associates.

Rosete, D. and Ciarrochi, J. (2005). Emotional intelligence and its relationship workplace performance outcomes of leadership effectiveness. Leadership \& Organization Development Journal, 26, (5), 388-399.

Salovey, P. and Mayer, J.D. (1990). Emotional intelligence, imagination. Cognition and Personality, 9 (3), 185-211.

Shanker, M. and Sayeed, O. B. (2006). Assessing emotionally intelligent managers: Development of an inventory with managers professional development. Journal of Industrial relations, 4(2), 227-251.

Stein S. J., Papadogiannis, P., Yip J. A., and Sitarenios, G., (2009). Emotional intelligence of leaders: a profile of top executives. Leadership and organization, 30(1), pp. 87-101.

Thorndike, E.L., (1920). Intelligence and its use. Harper's Magazine, 140, 227-235.

Walter F., Cole M. S. and Humphrey H. R. (2011). Emotional Intelligence: Sine Qua Non of Leadership or Folderol? Academy of Management Perspectives, Vol. 25, (1), 45-59.

Wolff, S.B., Druskat, V.U., Koman, E.S. and Messer, T.E. (2006). "The link between groups emotional competence and group effectiveness", in Drusksat, V.U., Sala, F. and Mount, G. (Eds), Linking Emotional Intelligence and Performance at Work, Mahwah, NJ: Lawrence Erlbaum Associates, 223-428.

This is an open-access article published and distributed under the terms and conditions of the $(c c) E_{\mathrm{EY}}$ Creative Commons Attribution 4.0 International License of United States unless otherwise stated. Access, citation and distribution of this article is allowed with full recognition of the authors and the source.

Authors seeking to publish with an International Peer Reviewed Journal should consider www.ijcab.org by writing to the Editor at editor@ijcab.org. 